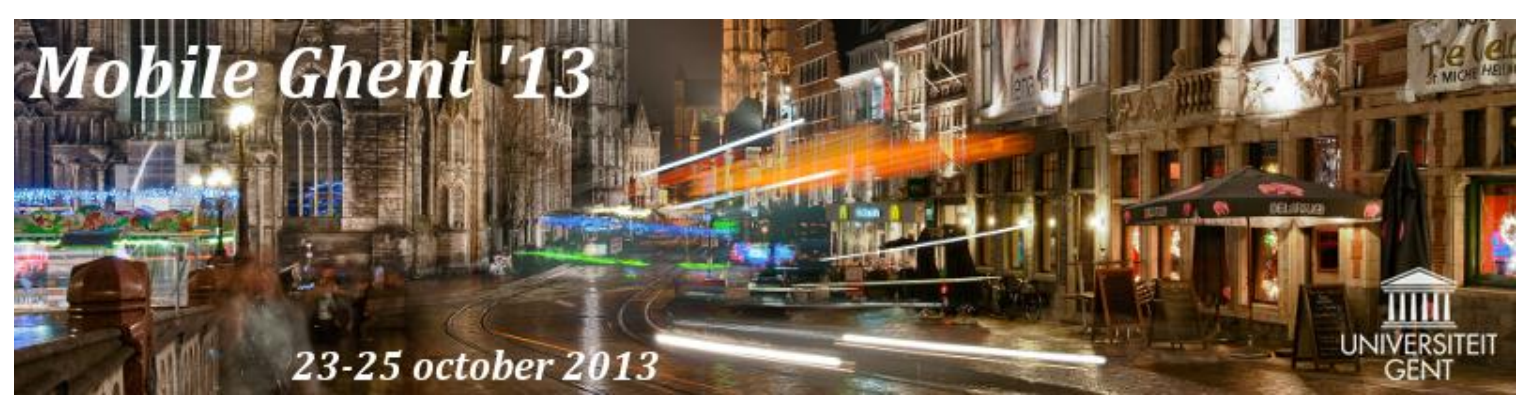

\title{
Shopping centre siting and modal choice in Belgium: A destination based analysis
}

\author{
Ward Ronse ${ }^{1}$, Kobe Boussauw ${ }^{1,2}$, Dirk Lauwers ${ }^{1}$ \\ ${ }^{1}$ Centre for Mobility and Spatial Planning, Ghent University, Vrijdagmarkt 10/301, \\ 9000 Gent, Belgium \\ ${ }^{2}$ Department of Geography, Ghent University, Krijgslaan 281-S8, 9000 Gent, \\ Belgium
}

tel. +3293313259 - email: ward.ronse@ugent.be

In the literature, modal choice is considered as a determining factor in the sustainability of travel patterns. Travel mode choice has an important impact on social issues such as traffic congestion, air pollution and climate change. In Belgium, the large share of car travel increasingly causes road congestion and hence, reduces accessibility. Spatial differences in modal choice prove to be highly associated with availability of transport infrastructure and the existing spatial structure. Within daily travel patterns, a large fraction is represented by travel for shopping purposes. Furthermore, characteristics of retail development such as location and size are variables that strongly determine overall spatial structure. Over the last decades, retail development is marked by an increase in scale and by suburbanisation trends. This is illustrated by the rise of shopping malls. The increase in scale forces new shopping centres to move to the edge of the city, as city centres do not offer sufficient space to meet the expectations of the developer. From a higher-level point of view, shopping centres operate as nodes in a polycentric urban system. In this context, particularly the suburban shopping malls can be seen as a European variant of the American edge city, attracting customers to the outer range of the city and consequently draining formerly thriving inner city centres.

Our hypothesis is that destination-based variables such as location and accessibility of shopping centres influence the travel patterns, specifically regarding modal choice, of the visitors. Based on an analysis of the modal split of the customers of seventeen 
existing shopping centres in Belgium, we develop a model for a more sustainable siting policy of shopping centres. Relying on both explorative and explanatory statistical data analysis we seek factors that significantly contribute to insights in the visitors' modal choice. The results show a major influence of the location of the shopping centre in relation to the urban form. For example, customers travel less often by car to shopping centres that are part of a dense urban fabric, measured by means of the population density in the range of one kilometre. The size of the shopping centre plays a role as well. Smaller sites will attract more cyclists and pedestrians. Then, based on the statistical results, we develop a classification of shopping centres in Belgium. This classification takes into account modal choice, city size, and location and size of the shopping centre. In addition, the defined categories are used to develop a number of policy recommendations. For example, it is highly recommended to integrate shopping centres into the existing urban structure rather than excluding them. Also, the size of shopping centres should be adjusted to the city size. In larger cities, occurrence of multiple shopping centres across the urban area is recommended. However, in order to serve the suburban population as well, the outer range of these cities need to supply also more car-oriented shopping centres. These suburban-oriented facilities should be part of a rather high-density network of relatively small shopping centres, thus reintroducing proximity in the suburbs. We conclude that, in case a more sustainable travel pattern is to be pursued, both characteristics of the built environment and of the facility itself should be taken into account when siting new shopping centres. 